\title{
Does Size Matter? How Firm Size Affects Social Externalities and Community and Regional Development
}

\author{
Christopher Lowe
}

\begin{abstract}
This study shows how family firm size affects the extent to which bus and coach operators in Australia interact with and contribute to their community by quantifying the value of eight social externalities and presenting the results, using the number of staff and the number of buses per operator as the denominators. The study highlights how a transaction between the government, as buyer, and the bus operator, as seller of services, can affect an external factor that being community and regional development. The results suggest that the small- and medium-sized family firm bus operators are the governance models most likely to contribute toward achieving community and regional development outcomes, which in turn, highlights the importance placed on the achievement of the non-financial goals of family firms and the socio-emotional wealth of the community in which it is embedded. This study suggests that it is possible that contracting bus-services for social value, rather than just lowest price, would create greater benefit for the community and this would offset any gains in economic efficiency achieved by large and non-family firms.
\end{abstract}

\section{Keywords}

Family business, social externalities, community development, governance

From Marx to Schumpeter, theorists have predicted the long-term triumph of large, publicly held firms at the expense of closely held family firms (Salvato and Aldrich 2012: 125). Yet today, many academics assert that family firms and small and medium-size enterprises (SMEs) are vital to the local, national, and global economy (Gama and Galvao 2012; Sharma, Chrisman, and Gersick 2012; Speckbacher and Wentges 2012).

Family firm bus and coach operators have embedded themselves into Australian communities, in most cases, over generations. Bus operators and their families in Australia are typically more than bus operators; instead, they perform several roles within their community and generally have more than one business concern. Bus operators display a level of local leadership that is valuable and significant; however, until now, the economic value of this community interaction has remained unknown.

This study identifies eight community interactions or social externalities, as a result of interviews with bus operators all over the world during the period 2012-2014. These externalities are then quantified by analysing the results of a survey of Australian bus

\footnotetext{
aMonash Sustainability Institute, Australia

Correspondent Author:

Christopher Lowe, 450 Graham Street, Port Melbourne, VIC 3207, Australia

E-mail: clowe@busvic.asn.au
} 
operators undertaken in early 2014 as part of the author's doctoral research project. The research question is: Does one size of bus operator interact with their community more than bus operators of other sizes? The results of this study suggest that size does matter that the behaviour of small- and medium-sized family firms is the governance model most likely to contribute toward achieving outcomes that are in line with community and regional development. Such an observation highlights the importance placed on the achievement of the non-financial goals of family firms and the socio-emotional wealth of the community in which it is embedded.

The paper is structured as follows: Following the introduction to the topic, some definitions and context of the Australian bus and coach industry will be presented. Section 3 presents a literature review in the fields of externalities and firm size, then offers a theoretical construct that could underpin a family business's community interaction and orientation: the "family point of view" (Sorenson et al. 2009). In Section 4, eight external value additions (or social externalities) are introduced, presented as community interactions that the author has identified, informally since 2008 in the management of the Victorian voluntary professional association for bus operators, and formally since commencing a doctoral research project on this topic in 2012. Section 5 presents the research question, a hypothesis and the methodology applied to value the community interactions. Section 6 then contains the results of the statistical analysis, where it is found that the hypothesis is supported. In Section 7, there is a discussion of the implications of the results of this study. Section 8 concludes the study with a recommendation that the policy be adopted that sustains the small- to medium-sized family firm as a governance model for bus operators, as this will contribute toward achieving community and regional development objectives in Australia.

\section{DEFINITIONS AND CONTEXT}

This section provides some context for the Australian bus- and coach-operating environment and defines the key themes of this study.

\section{Definitions}

An externality is defined as a benefit or cost incurred by an incidental party as a result of an activity. A voluntary exchange between two parties is considered mutually beneficial, however, the transaction can have additional effects on third parties. These effects can be positive or negative and are referred to as externalities. This study identifies and then quantifies the value of the externalities of a social nature that result from the exchange between the government (buyer) and the bus operator (seller) that affect a community.

In Australia, there is no official definition of a family business. In fact, there is an absence of consensus on what defines a family business and this was the subject of an Australian Senate Committee Inquiry in 2012. Shanker and Astrachan (1996) suggest that the criteria used to define a family business can include: percentage of ownership, voting control, power over strategic decisions, the involvement of multiple generations, and active management by family members. For the purposes of this paper, however, Family Business Australia's (2013) definition has been adopted:

A family business is comprised of two or more members of the same family involved in the business with one or more related members having a controlling interest. (Family Business Australia 2013)

While firm size in the Australian bus and coach industry is often measured in terms of the number of buses, the number of employees, and turnover, this study uses the Australian Bureau of Statistics' (ABS) (2013) employment-based definition of size. This definition classifies large businesses as employing 200 or more persons, medium businesses as employing 
between 20 and 200 persons, and small businesses as employing less than 20 persons. Each definition is then modified slightly to suit the context of the industry and be in keeping with the general understanding of Australian bus and coach industry personnel as to what constitutes a small, medium, and large bus operator. The number of staff and number of buses are the two unit bases of measurement adopted for this study. Firm turnover, which is not used in this study, will be used, however, as a third denominator in the author's doctoral project.

This study adopts Cavaye's (2014) definition of community development, which is a broad term describing the practices of civic activists and involved residents who are concerned with the building of stronger and more resilient local communities. Similarly, regional development, as defined by the OECD (Organization for Economic Co-operation and Development) (2014), is another broad term to denote the general effort to reduce regional disparities by supporting regional economic activities that generate employment and wealth. Regional development concerns the economic and social improvement of infrastructure, improved community services, a greater and more diverse volume of production, lower unemployment, an increased number of jobs, rising average wealth, and an improved quality of life (McCall 2010).

\section{Context}

The Australian bus- and coach-operating environment is composed of approximately 5,000 family firms. There are also fewer than 10 non-family firms with rights to operate bus services throughout Australia and these comprise both government-owned operating entities and multinational firms. Of the 5,000 operators, approximately $30 \%$ belong to a state-based voluntary professional bus association, although there are different operator/member ratios in each state. Family firm bus operators are typically trans-generational businesses. Some operators have expanded their operations to other states and some operators' businesses are, in fact, supplementary or secondary businesses that support a primary business, such as a farm.

Bus and coach operators generally fall into three categories: those who are predominantly or exclusively route bus operators, those who are predominantly or exclusively mainstream school or special school bus operators, and those who are predominantly or exclusively charter bus and tour bus operators. On enquiring into the number and nature of operators that do not belong to state-based voluntary professional bus associations, the author was informed that virtually all government-contracted route and school operators belong to these associations. The majority of non-member operators are charter bus and tour bus operators with no government contract who have a reduced "need" for representative services.

Most of Victoria's route bus services were started by families between the 1920s and 1970s with minimal government involvement; they received authority from the state to operate a bus service in the form of a licence, but operators used to set their own fares and carried all of the operating risk. Since then, legislation and regulations have modernised and increased as social policy has evolved. In the 1970s, most states decided to regulate fares across the whole public transport system in order to make public transport affordable and accessible. In return, the government paid the operator a subsidy for the fare or the revenue that would be foregone for charging a certain demographic of passenger a lower fare. Since then, all state governments have assumed all operating risks and subsidised all costs associated with delivering the contracted service.

The school bus operator sector in Australia has a similar history to that of the route bus operator. Some school bus services started on the back of dairy businesses when farming families voluntarily took children to school. State governments began to formalise this sector at the end of the Second World 
War and most new services have been tendered for many years, however, many existing bus-service contract holders today are descendants of the original operators. There are virtually no mainstream school buses in metropolitan Melbourne.

Despite the predominance of family-owned businesses in the bus operating sector, however, operators have consolidated at a rapid rate since 2005 . In Victoria, the number of small bus operators (with fewer than 10 buses) declined by around 30\% during the period 2005-2013 and the number of medium-sized family bus operators (with 10-99 buses) also declined during the same period. Conversely, the number of large operators (with more than 100 buses) more than doubled during the same period (from six to 13) and other Australian state-based voluntary professional associations have reported similar trends. During this time, the governance of large bus operators has changed from consisting almost entirely of family firms and a few government-owned entities in 2005, to consisting of family firms, government entities and non-family, public, and multinational firms in 2013. The author's doctoral research project will discuss the reasons for this consolidation and the emerging changes in operating governance. Today in Victoria, $83 \%$ of all operators are considered as "small" (one to nine buses), 14\% are considered as "medium" (10-99 buses), and 3\% are considered as "large" (100 buses or more). Eighty-five percent of operators are located outside of metropolitan Melbourne.

The survival and longevity of the family firm bus operator governance model has seen that most bus operators become embedded in the community and region in which they operate and, in doing so, they have assumed many additional civic roles over the years. Before the community interactions (social externalities) are discussed in detail, a review of the literature on externalities, firm size, and the "family point of view" construct will be given.

\section{LITERATURE REVIEW}

This section summarises the scholarly publications on the three central themes of this study: externalities, firm size, and the "family point of view", a construct which appears to explain a family business' community orientation and interaction (Sorenson et al. 2009).

\section{Social Externalities}

Studies on social externalities are scarce; as far as the author is aware, there has been no attempt to quantify social externalities according to the behaviour of a group of persons or organisations by industry, probably due to a lack of suitable pricing of the effect that gives rise to the externality. Further, other than the National Institute of Economic and Industry Research's (2011) “Melbourne Route Bus Contracts: The Impact of Change From Local to Non-local Ownership", the author is unaware of any study that identifies and quantifies the value of social externalities and any economic outturn associated with these, categorised by firm size.

Several scholars have, however, discussed externalities in different contexts. Eapen (2012) and Sinani and Meyer (2004) discuss whether the presence of foreign firms in a host market leads to technology externalities and the upgrading of domestic firms. Grinols and Mustard (2001) provide a framework to address the theoretical cost-benefit issues of casinos by grounding the cost-benefit analysis on household utility and the current state of knowledge about the estimates of both the positive and negative externalities generated by casinos. Aldrich (2011) demonstrates how high levels of social capital simultaneously provided strong benefits and equally strong negative externalities, especially to those on the periphery of society, in the post-tsunami recovery in South-East India. The aforementioned studies discuss economic and environmental externalities and centre on different industries and circumstances. They have 
elements of similarity to this study, however, and they focus on social capital (which will be included in one of the author's future studies).

\section{Firm Size}

The question "Does size matter?" is the key question addressed in this study. Numerous scholars have written on the link between governance and performance, but scholarly work that investigates any correlation between firm size and societal outcomes, such as community and regional development, is rare. Most scholarly articles concentrate on the strengths and weaknesses of the small, typical family businesses and the large, non-family enterprise; the latter usually includes a discussion of the virtues and vices of the foreign direct investment enabled by multinational firm governance. Other researchers have written on the capabilities and benefits of being small or large in business and on whether size affects performance (Birley and Norburn 1993; Winger 1994; Kotkin 2000; Dumaine and Labate 1992; Williams 2013).

Vossen (1998) writes that the relative strengths of multinational firms lie mostly in resources, while those of small family firms are described in terms of behavioural characteristics. This suggests that large firms are better at innovations that make use of economies of scale and scope, or require large teams of specialists, such as fundamental, science-based innovations, and large-scale applications: innovations with a high average economic value. Small firms are likely to be relatively strong in innovations where the effects of scale are not yet important and where they can make use of their flexibility and proximity to market demand, such as new products or modifications to existing products for niche markets and small-scale applications. Matters related to firm size, and multinational firm governance in particular, should be included in the discussion of the literature associated with foreign direct investment and transfer pricing, as these phenomena are exclusive to large, non-family firms, some of whom completed this survey.

The literature on the effect of foreign direct investment is typically inconclusive and controversial, but is necessary in the context of this research because multinational firms are a governance model of increasing importance in the Australian bus-operating environment. Foreign direct investment is the direct investment into production or a business in one country by a company in another country. Transfer pricing refers to the prices charged in intra-company transfers of goods and services in multinational firms. Transfer pricing is an important consideration in this thesis as it presents a point of difference and possible competitive advantage to large, multinational bus operators when pursuing growth strategies (in terms of being able to move profit among tax jurisdictions with differential tax rates, minimising total corporate tax, and maximising returns to shareholders). This is, therefore, an area in which small to medium, local, family business operators generally do not, and most likely cannot participate.

Large firms, however, also have their drawbacks and small firms have other advantages over large firms. With respect to large firms, Lawler and Galbraith (1995) suggest that size has not assured large, multinational firms of success; rather, it causes them to become internally focused and concerned with maintaining and managing their internal relationships. The authors suggest that large firms become more bureaucratic and control-oriented as a way of coping with the coordination and communication problems that result from their large size. In small firms, on the other hand, Moates and Kulonda (1990) suggest that there is a sense of teamwork among supervisors, superiors, and employees, a clarity of the company mission and individual responsibilities, a closeness to the customer, easier and more intense communications and a stronger sense of personal identity. The authors make a point that bears relevance to this study, to an extent: 
An important question that remains to be answered is whether or not the differences identified lead to increased effectiveness. If small companies are indeed more effective, then improvements in large companies might result by identifying the underlying causes for this effectiveness and applying them in larger companies. This potential for improvement makes future research into small company performance and effectiveness, along with an effort to identify specific causes of observed size-related differences, a priority issue. (Moates and Kulonda 1990: 35)

\section{The "Family Point of View"}

Sorenson et al.'s (2009) work on the "family point of view" is drawn on this paper because it appears to explain a family firm's community interaction and orientation. The authors' work examines business governance systems and how they are used to identify and develop assets that benefit the family's objectives, the business itself, individuals, and communities. They suggest that good governance of both the business and the family requires family members to develop a shared point of view toward the business and their involvement in it-that is, the "family point of view". Sorenson et al.'s (2009) empirical analyses confirm that a positive relationship exists between collaborative dialogue and ethical norms, between ethical norms and family social capital, and between family social capital and firm performance. The "family point of view" is thus the united family perspective, achieved through collaborative dialogue and shared ethical norms.

When families establish a business, the beliefs and norms that are important to the family tend to carry over to the business. This inheritance or "passing on" of beliefs and norms is one of the characteristics that make family companies distinctive (Sorenson et al. 2009). The authors found that extensive collaboration within the family was associated with an increase in the resources available to the family business, including loyal customers, family support and, critically, community goodwill. Family members who understand and participate in the governance of the enterprise can work with the business to prepare other family members to be potential employees, leaders, board members, active shareholders, community representatives, and participants in family foundations and philanthropy. In turn, being well-resourced delivers "positive family social capital" (Sorenson et al. 2009: 242), which is founded on positive network relationships among the family, employees, customers, and community members, and implies that "An emphasis on ethical norms helps to build enduring network relationships" (Sorenson et al. 2009: 250). With these perspectives in place, the following section details the social externalities, or community interactions, identified as part of a broader study which is the author's doctoral research project.

\section{THE EXTERNAL VALUE ADDITIONS}

In this section, eight social externalities, described as community interactions, are described in detail. These have been identified by the author, informally since running the Victorian voluntary professional association for bus operators since 2008, and formally since commencing a doctoral research project on this topic in 2012 that has included interviews with bus operators around the world and a formal survey of over 1,600 bus operators Australia-wide. The author's doctoral research project looks at the causal factors relating to an operator's community interaction and orientation, including that of size.

To identify how bus operators, on both a global basis and specifically in Australia, interact with their communities, the author undertook more than 20 formal interviews across Australia, New Zealand, United Kingdom, Canada, the United States of America, Norway, Finland, and Denmark. Appointments were made via connections at both local and overseas transport businesses, industry associations, and universities. 
Trends emerged very early during the formal interviews that confirmed that bus operators' behaviour, in relation to their interaction with their communities, is virtually the same throughout the countries that were investigated. Small, medium, and large bus operators all over the world, be they family or non-family firms, have an orientation and degree of interaction with the communities they service, although the extent of that orientation and interaction differs pursuant to several variables, including firm size.

As a result of undertaking the interviews, the author was able to place the types of community interactions and the added value to the community into the eight categories that are described in the following sub-sections, typically by asking operators how frequently they might interact with their community and what value they place on each interaction. The following interactions (or externalities) all have a value, which this study will quantify in relation to firm size, illustrating an under appreciation of externalities. These interactions illustrate the manner in which the quality and quantity of social interaction within a bus operator's geographic community - and community of interest can affect the social and economic wellbeing of the community, and ultimately, Australian society.

Table 1 shows the eight social externalities in four groups.

\section{Discount Services}

Discounted (or underpriced) services denote the community interaction in which bus operators provide bus services at either complimentary or discounted prices to local organisations and individuals. Below is one example taken from an interview with a bus operator:

We make sure that our kids are denied nothing. We take them to events in (nearby town name withheld), all around the district. In fact, either at cost or for free. Years ago, the school started a travel fund. The parents contributed via the school fees to pay travel costs. It started in the early 60 s and it is still going to this day. When we started it, I guess it was known as "innovation", but we are reaping the benefits now.

\section{Financial and Non-Financial Donations}

Financial and non-financial donations refer to the community interaction in which operators donate money or general goods and services, such as utility bills, food, or clothes, to organisations and individuals. Below is one example taken from an interview with a bus operator:

We also fund five indigenous children's annual travel pass costs so they can get from home to school. This equates to $\$ 880$ per student per year. We believe this is our social responsibility to keep kids in school, because it has been made clear to us that there are some students who, without our services, may not be able to get to school.

\section{Sponsorships}

Sponsorships denote the community interaction in which operators sponsor the initiatives of local and non-local individuals and organisations, such as schools, students, and local sporting clubs, as well as local and international charities. For example:

We are sponsoring an Afghan lad now. We don't tell anyone about it, nor does he know we are sponsoring him. It costs us around $\$ 18,000$ a year and the school just sends us the bill. I'm not alone. I know of several operators in my area who do this sort of thing, because it's our town. We also sponsor footy clubs, soccer clubs, and other sporting bodies, as they unite our community. I say this a lot, but it's all about community wellbeing.

\section{Time Contributions}

Time contributions refer to the amount of time operators contribute to civic organisations, such as serving as office bearers on community boards and in philanthropic organisations. Many of the bus operators interviewed for the author's research project were a 
Table 1. Social Externalities/Community Interaction Groups

\begin{tabular}{|l|l|}
\hline Group and definition & Community interaction \\
\hline $\begin{array}{l}\text { Opportunity cost } \\
\text { Revenue foregone, being the sum of frequency of an interaction multiplied by a a } \\
\text { specified unit rate as indicated by survey respondents }\end{array}$ & $\begin{array}{l}\text { Discounted services } \\
\text { Time contributions } \\
\text { Sharing resources }\end{array}$ \\
\hline $\begin{array}{l}\text { Costs incurred } \\
\text { Costs incurred by the operator, being the frequency of an expense incurred } \\
\text { multiplied by a unit cost as indicated by survey respondents, or just set annual } \\
\text { unit costs as indicated by survey respondents }\end{array}$ & $\begin{array}{l}\text { Financial \& non-financial donations } \\
\text { Sponsorships }\end{array}$ \\
\hline $\begin{array}{l}\text { Interactions } \\
\text { The frequency of an interaction without unit rate values }\end{array}$ & $\begin{array}{l}\text { Safety \& security } \\
\text { Purchasing behaviour }\end{array}$ \\
\hline $\begin{array}{l}\text { Revenue received } \\
\text { Income received, being the sum of the frequency of an interaction multiplied } \\
\text { by a specified unit rate as indicated by survey respondents }\end{array}$ & Combining resources \\
\hline
\end{tabular}

volunteer with the Country Fire Authority (CFA), a board member of a community hospital, and an office bearer of a sporting club, and dedicated their time to these local institutions. One example from an interview with a bus operator is as follows:

I sat on the (town name withheld) development association for many years; I was director of the (organisation name withheld) for some time; I'm very involved in the local Apex and Lions clubs. My father, who started the business, sat on the local hospital board for a very long time, he was also on the board of the local RSL (Returned and Services League). My son's wife has recently been appointed to the (area name withheld) adult-education board and both he and his wife are office bearers at the local football and netball clubs.

\section{Safety and Security Contributions}

Bus operators, bus drivers, and bus passengers can make safety and security contributions that involve established relationships between operators and passengers, increasing passenger safety and security. This is a community interaction which cannot be quantified on a time basis (i.e., number of hours multiplied by rate of pay), but it is a community interaction nonetheless. Below are two examples of this:

We know all our kids as well. We know all the parents.
When the parents are not at a bus stop when the bus arrives we don't ring them, we just bring them back to our house, then we ring the school and the parents come and collect them from our house. This shows the level of trust between ourselves and the parents. The school often advises us of drop-off and pick-up changes because of special circumstances and we are happy to oblige.

We often get off with the kids on the side of the road and ensure they cross the highway safely; we also wait at the stop if a parent is not at the stop. We also ring the parents and wait.

\section{Purchasing Behaviour}

Purchasing behaviour involves community contributions made by reinvesting income from the bus service in the local community to spur economic development. Some examples from interviews with bus operators include:

I'd reinvest at least $75 \%$ of my income in the (region name withheld) economy. Another bus operator entered the (town name withheld) market, as they won a service via tender. It was a special school bus service and the government told me that I lost it because the other operator was cheaper. When I pointed out to the government that the other operator was taking that contract value out of (town name withheld, but another regional centre) and putting it into (other town name withheld), they did not care one bit. That's one less job for my town. This is my town. I live here and so I want to make it as good as possible for everyone. When I bid for a tender I make sure that I talk about my capacity to reinvest the contract money locally. 
The only thing I don't buy locally is spare parts. My fuel, paint, windows, and labour are all bought here. We are very loyal to local businesses because if we did not invest in their firms, it would have a knock-on effect that would be disastrous. I know things probably cost a little bit more, but it keeps those families in business and, importantly, it keeps the services in our town. One of the towns we operate in is very small and I employ six full-time people there. If I really wanted to, I could probably satisfy my need with four part-time drivers, but if I was to do that, that would hurt the local economy and I think the local service station where I get my fuel from would close.

The six community interactions outlined above constitute social externalities that demonstrate bus operators' interaction with the community stakeholders such as passengers, parents, schools, residents, and staff. The following two social externalities demonstrate how bus operators interact with fellow bus operators.

\section{Sharing Resources}

Sharing resources involves the interaction of operators who share different types of resources or assets (mainly buses, bus drivers, and equipment) with each other when needed to ensure a bus service is able to continue operating. One example of this from the interviews with bus operators includes one operator who loaned a bus driver to a nearby operator because the regular driver was unable to work. Another example is one operator who loaned a spare bus and parts to a nearby operator because the regular bus was temporarily unserviceable. These types of interactions are generally executed on an underpriced basis because of the extent of reciprocity that exists between operators.

\section{Combining Resources}

Combining resources involves the interaction of multiple operators who combine their various forms of capital to present themselves as a single operator (or contractor) for large people-moving tasks that might be necessary for events such as planned and unplanned rail replacement work. The demand associated with such high-volume work can rarely be satisfied by one operator and, therefore, metropolitan and regional operators (in some cases up to 45 operators) leverage their social capital and cooperate to combine resources in a manner that satisfies the client's budget and time requirements, as well as the passengers' transport needs.

Having described the eight social externalities (or community interactions) of bus operators, the next section will describe the methodology adopted to value these externalities.

\section{Study Question and Hypothesis}

The question this study asks pursuant to firm size is: Does one size of bus operator interact with their community more than bus operators of other sizes? As a result of observing operators' behaviour since 2008, the following hypothesis was developed: A bus operator's community interaction diminishes as firm size increases.

\section{METHODOLOGY}

A survey was developed between October and December 2013 as part of the author's doctoral research project, consisting of 29 questions, seeking qualitative and quantitative answers, divided into five sections. One of those sections was specifically related to firm size, ownership, and control, and this study relates to that section of the survey only. The survey was sent to 1,623 bus operator members of six state-based voluntary professional bus associations and eight bus operator members of the one, federal, bus industry representative group in January 2014. All recipients were requested to complete and return the survey by March 7, 2014.

When the surveys were returned, all quantitative 
Table 2. Survey Response Rates (\%)

\begin{tabular}{lllllllll}
\hline & VIC & NSW & QLD & TAS & SA & WA & ACT & Total \\
\hline Surveys sent & 424 & 526 & 187 & 185 & 45 & 255 & 1 & 1,623 \\
Surveys returned & 98 & 73 & 24 & 24 & 5 & 52 & 0 & 276 \\
Survey capture ratio & 23 & 14 & 13 & 13 & 11 & 20 & 0 & 13 \\
\hline
\end{tabular}

Notes: VIC-Victoria, NSW-New South Wales, QLD-Queensland, TAS-Tasmania, SA-South Australia, WA-Western Australia, ACT-Australian Capital Territory.

information was entered into Statistical Package for the Social Sciences (SPSS) and all qualitative information was entered into Excel. The quantitative information was calculated in SPSS, exported to Excel for conversion into various graph formats, cross-tabulated and then copied into Word for ease of presentation. The number of survey responses varied from state to state as seen in Table 2:

After seeking advice from two independent statisticians, $13 \%$ of survey response rate was deemed adequate to undertake individual community interaction and overall statistical analysis, but not adequate for state-specific analysis ${ }^{1}$.

Each of the eight community interactions will now be individually quantified and presented, followed by an aggregated total of community interactions. With respect to the aggregated total, the sum of only six community interactions per staff member has been calculated: First, the safety and security interaction has been excluded (because it is only an interaction and does not attract a unit value per interaction); and second, the local purchasing interaction has been excluded (because the results are in the tens of millions, while the other six community interactions are measured in the hundreds or thousands, and the purchasing behaviour of large operators skews the results significantly). Of the nine "large" survey responses, seven are family businesses and only two appear to be non-family operators. Furthermore, one of the two non-family operators was almost completely unforthcoming regarding the eight community interactions, including providing no information about purchasing behaviour, hence the exclusion of the local purchasing interaction.

This study takes the denominator "per staff member" and cross-tabulates this with the denominator "per bus" in order to divide up the 276 survey respondents and, as such, variables were created in SPSS and applied to each of the eight community interactions as per Table 3 :

These denominators were adopted for two reasons: First, these metrics resemble the ABS's definitions of small, medium, and large businesses, thus accommodating one of the two main denominators associated with measuring firm size, that is, the number of staff; second, these groupings reflect the industry's general rule of thumb (and understanding) of what size constitutes a small, medium, and large fleet of buses.

The results are presented pursuant to the formula used: The "per staff member" variable is on the $\mathrm{Y}$ axis and the "per bus" variable is along the $\mathrm{X}$ axis to quantify and compare each bus company's behaviour for each community interaction.

An example of one of the variables created in SPSS for "per staff member" ( $\mathrm{Y}$ axis) was:

Name: "Discounts_per_Staff"

Label: "Total Discounts/Staff Member"

Units: "\$/staff/year"

Value: Survey Question $(q 12 c \times q 12 d) /(q 1 a+q 1 b)$ 
Table 3. Denominators for Dividing Survey Responses

\begin{tabular}{|l|l|l|}
\hline Code & Meaning & Explanation \\
\hline \#Buses & Total number of buses the firm runs & $\begin{array}{l}\text { The “\#Buses” category will be divided into three sub-sections: 1-9 buses } \\
\text { (small); 10-99 buses (medium); 100+ buses (large). Each interaction will be } \\
\text { valued in nominal dollars and no weighting will be applied. }\end{array}$ \\
\hline \#Staff & $\begin{array}{l}\text { Total number of staff (both full-time } \\
\text { and part-time) the firm employs }\end{array}$ & $\begin{array}{l}\text { The staff member category will be divided into three sub-sections: 0-29 } \\
\text { (small); 30-99 (medium); 100+ staff (large). }\end{array}$ \\
\hline
\end{tabular}

i.e., ("discount times per year" $\times$ "average discount size")/(“F/T Staff” + "P/T Staff”)

An example of one of variables created in SPSS for "per bus" (X axis) was:

Name: "Donations_per_Bus"

Label: "Total Donations/Bus"

Units: "\$/Bus/Year"

Value: $\mathrm{q} 13 \mathrm{~d} /(\mathrm{q} 8 \mathrm{a}+\mathrm{q} 8 \mathrm{~b}+\mathrm{q} 8 \mathrm{c}+\mathrm{q} 8 \mathrm{~d}+\mathrm{q} 8 \mathrm{e}+\mathrm{q} 8 \mathrm{f}+$ $\mathrm{q} 8 \mathrm{~g}+\mathrm{q} 8 \mathrm{~h}+\mathrm{q} 8 \mathrm{i}+\mathrm{q} 8 \mathrm{j}+\mathrm{q} 8 \mathrm{k}+\mathrm{q} 8 \mathrm{l})$

i.e., ("total value of donations per year")/("total number of buses")

Some data presented as non-normal (non bell shaped). For this reason, two contrast tests were used to compare the analysis of means:

(1) ANOVA on "Linear" data;

(2) ANOVA on "Ln" data ("Ln" denotes "Natural Logarithm")'

Given that the sum of the six items spans across negative values as well as positive values, it was not possible to take the logarithm of the "Overall Community Interaction" variable, as logarithms are undefined for negative quantities. An hourly labour rate of $\$ 35.00$ was used as the unit variable to be multiplied by the number of hours contributed in those community interactions that are temporal, in order to arrive at an estimated market value. This figure was used based on advice from a commercial advisor and the figure represents the average of all school, route and charter bus drivers' hourly rates of pay on a national basis.

The results are presented as a figure that has two parts: a box plot showing the mean values for linear data or natural logarithm ("Ln") data; accompanied by a table underneath the box plot which shows the corresponding contrast test comparison of means. The uncertainty bars represent a $95 \%$ confidence interval. Only statistically significant results are shown and are indicated as "*” or "“*”, and shaded in green.

\section{RESULTS}

On an aggregated overall basis of the six community interactions, small family firm operators contribute to their community by an average of $\$ 2,309$ per staff member per year, medium operators contribute to their community by an average of $\$ 1,134$ per staff member per year, and large operators contribute to their community by an average of $\$ 750$ per staff member per year. This result is displayed in Figure 8. All other individual community interaction cross tabulations pursuant to bus operator size are displayed in Figure 1 to Figure 7.

On an individual interaction basis, this analysis reveals that small bus operators interact the most with their community on a per staff member basis for four of the eight community interactions: financial and non-financial donations, time contributions, safety and security interactions, and the sharing of resources. Medium-sized operators interact the most with their community on a per staff member basis with discounted services, sponsorships, and local purchasing. Large operators interact the most with their community on a per staff member basis when it comes to combining resources with other operators. 


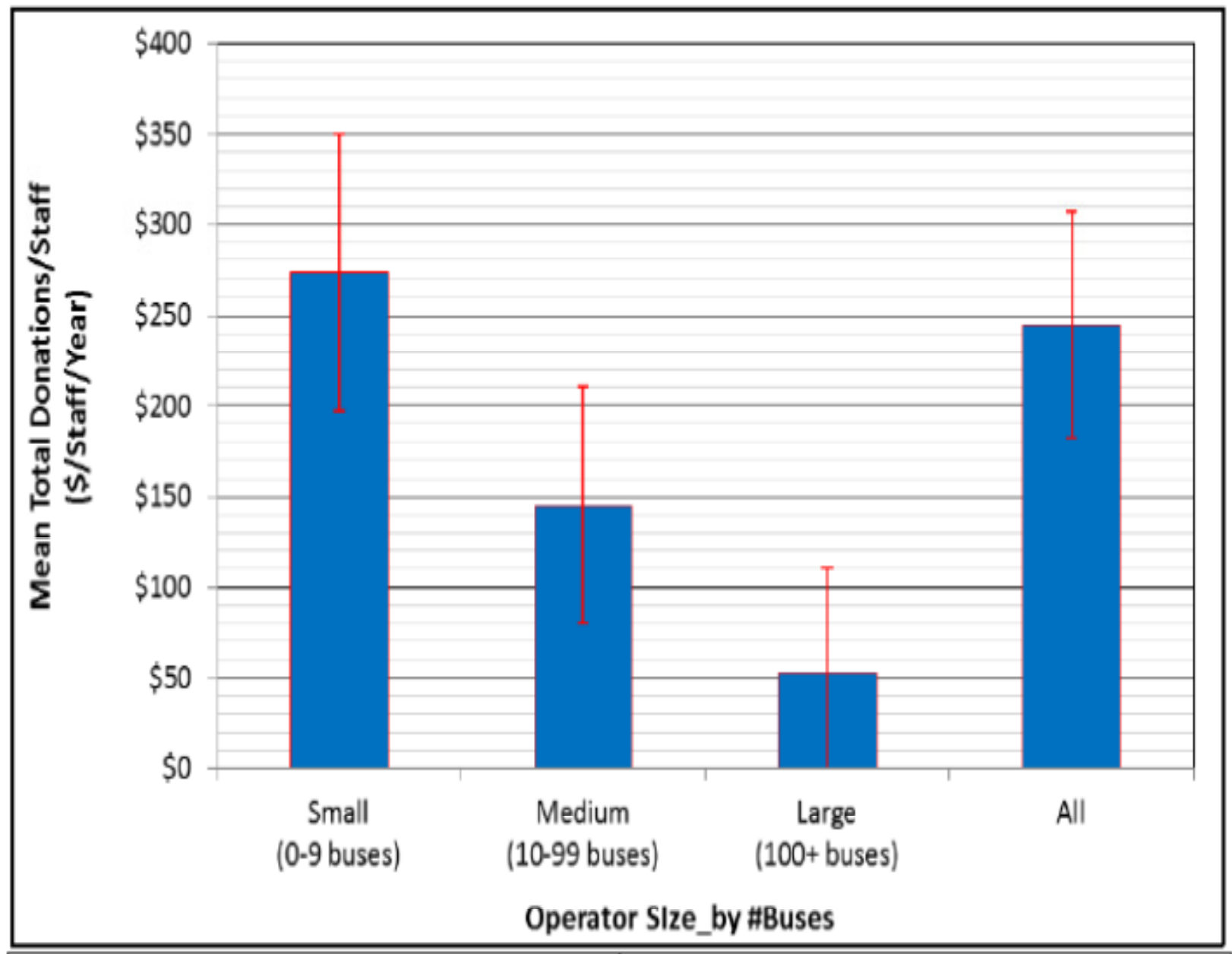

\begin{tabular}{|l|c|}
\hline Contrast (Operator Size by \#Buses) & $\begin{array}{c}\text { Sig. value for Alternative Test of } \\
\text { Contrast Significance. } \\
\text { One-Way ANOVA Test } \\
\text { (Linear data values) }\end{array}$ \\
\hline [Small - Medium] & $.011^{*}$ \\
\hline SSmall - Large] & $.000^{* *}$ \\
\hline [Medium - Large] & $.042^{*}$ \\
\hline
\end{tabular}

Figure 1. Mean Total Donations Per-Staff-Member, Resolved by Operator Size and Corresponding Contrast Tests. 


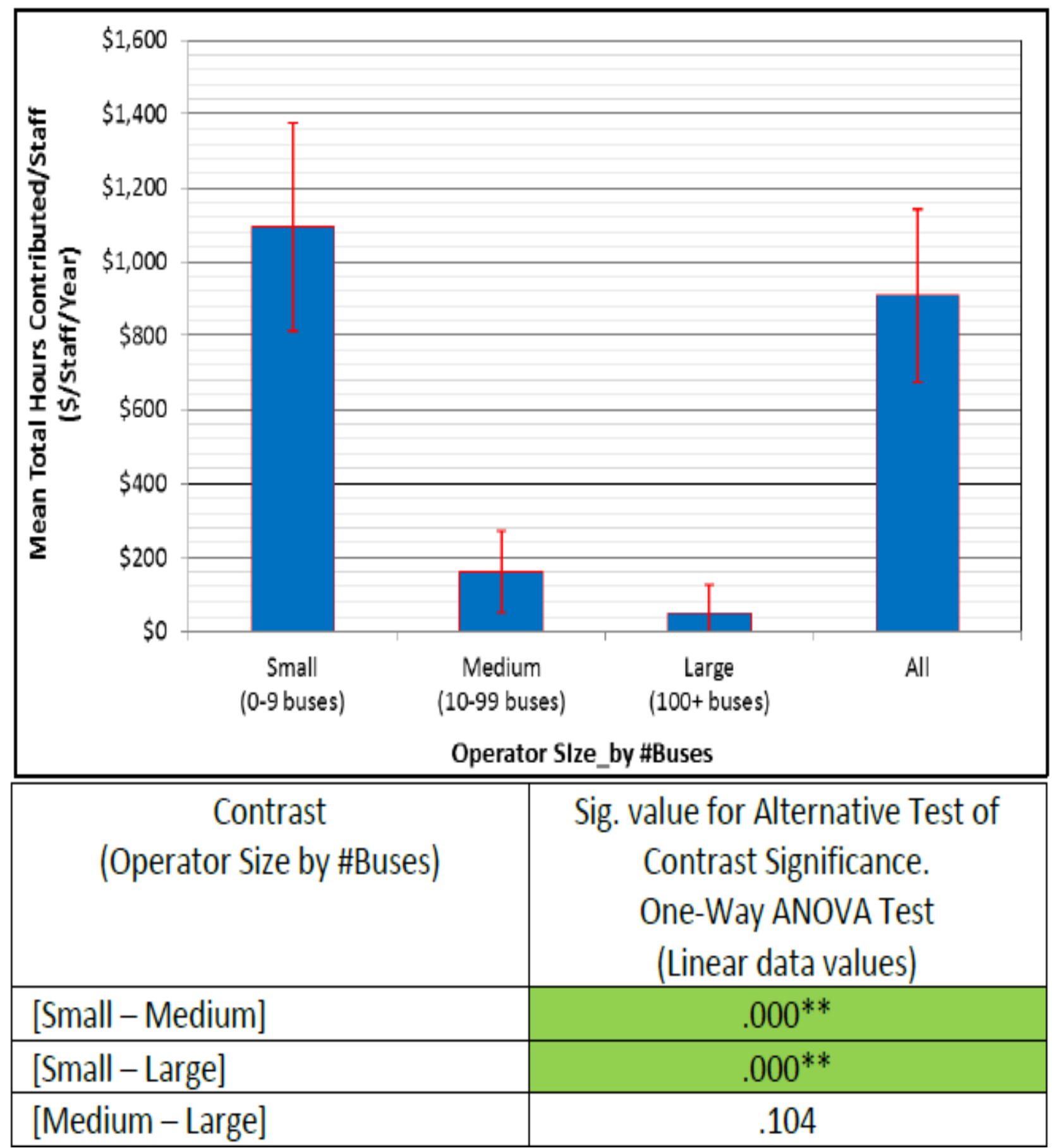

Figure 2. Mean Total Hours Contribution Per-Staff-Member, Resolved by Operator Size and Corresponding Contrast Tests. 


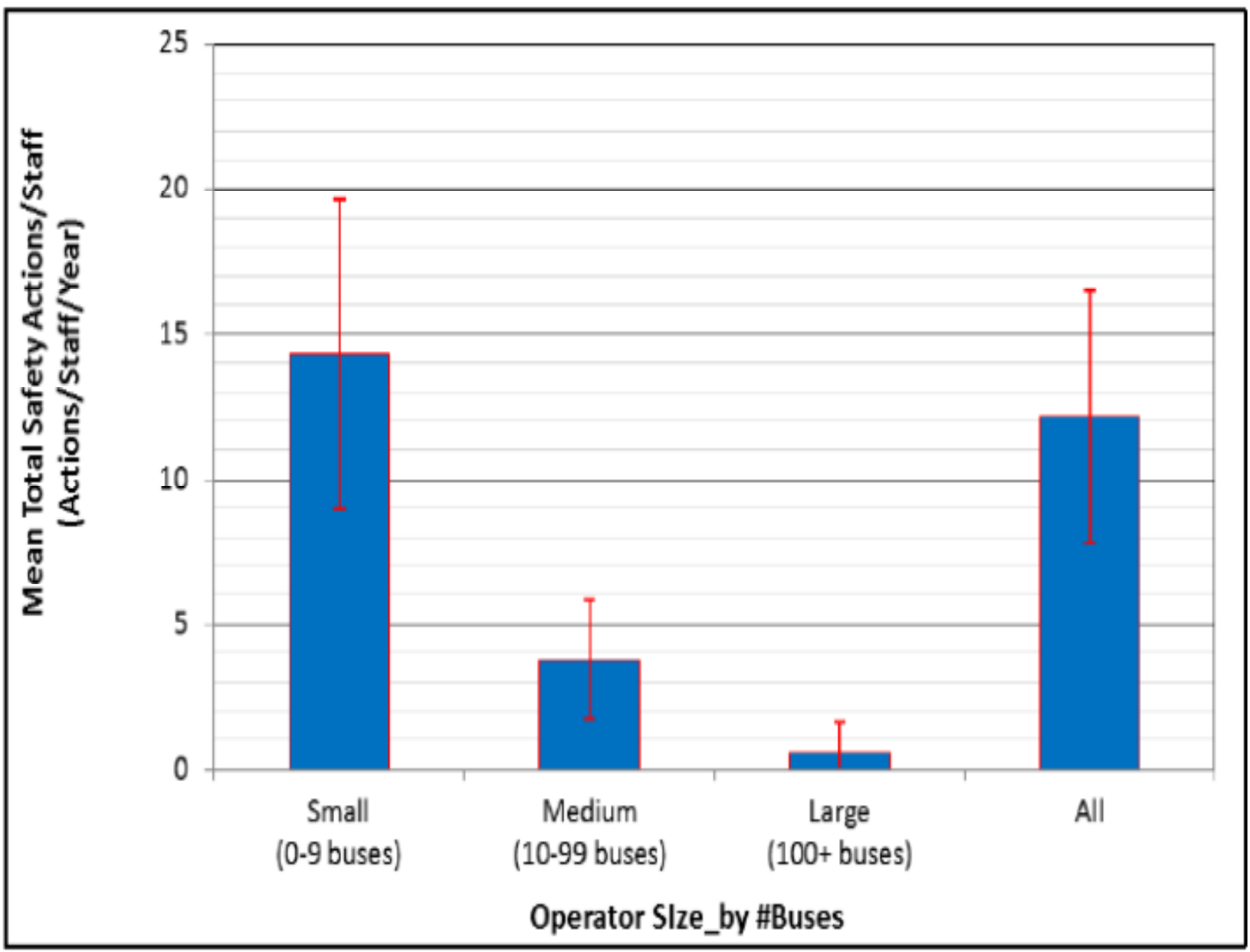

\begin{tabular}{|l|c|}
\hline \multicolumn{1}{|c|}{$\begin{array}{c}\text { Contrast } \\
\text { (Operator Size by \#Buses) }\end{array}$} & $\begin{array}{c}\text { Sig. value for Alternative Test of } \\
\text { Contrast Significance. } \\
\text { One-Way ANOVA Test } \\
\text { (Linear data values) }\end{array}$ \\
\hline$[$ Small - Medium] & $.000^{* *}$ \\
\hline$[$ Small - Large] & $.000^{* *}$ \\
\hline [Medium - Large] & $.009^{* *}$ \\
\hline
\end{tabular}

Figure 3. Mean Safety Interactions Per-Staff-Member, Resolved by Operator Size and Corresponding Contrast Tests. 


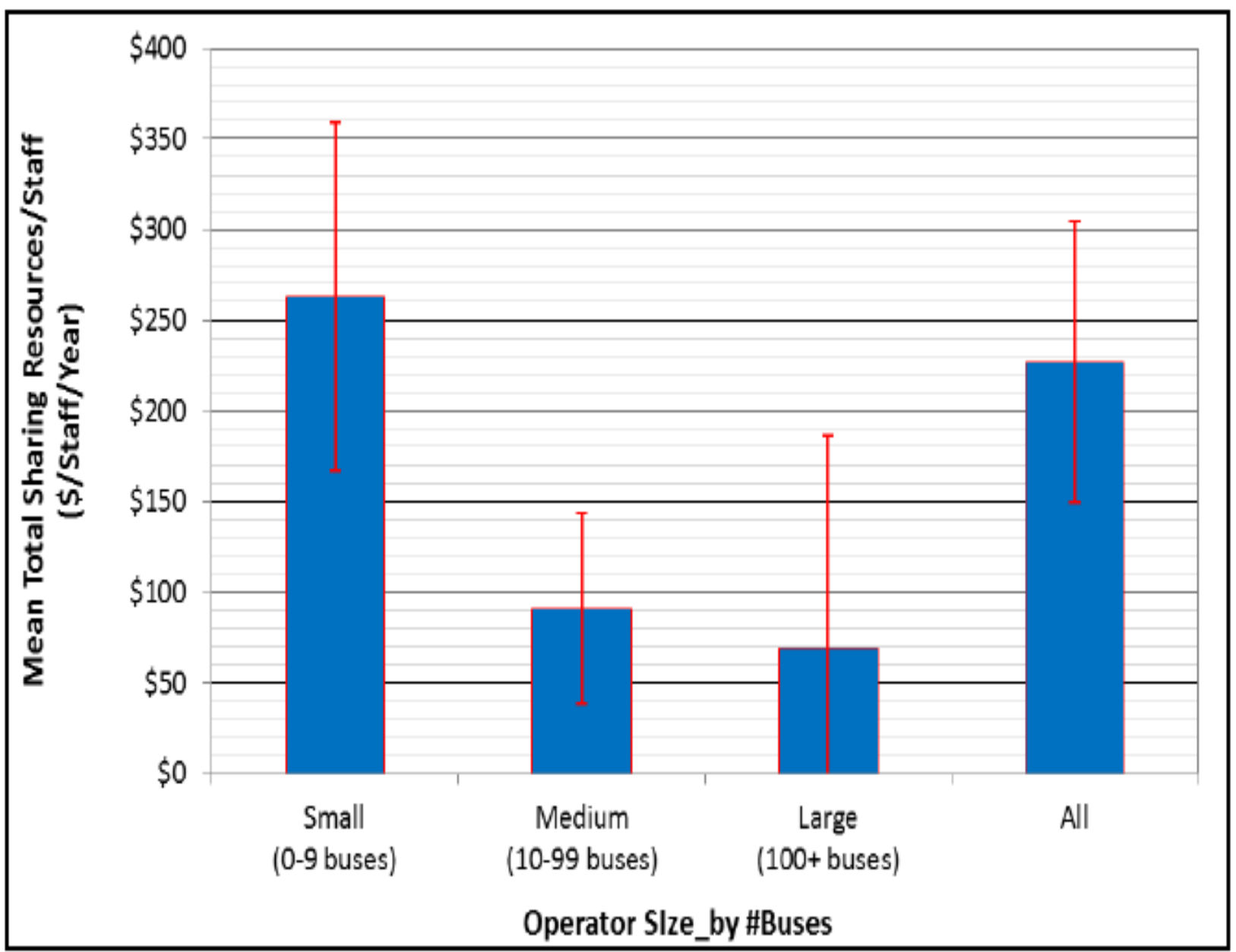

\begin{tabular}{|l|c|}
\hline \multicolumn{1}{|c|}{\begin{tabular}{c|} 
Contrast \\
(Operator Size by \#Buses)
\end{tabular}} & $\begin{array}{c}\text { Sig. value for Alternative Test of } \\
\text { Contrast Significance. } \\
\text { One-Way ANOVA Test (Linear } \\
\text { data values) }\end{array}$ \\
\hline [Small - Medium] & $.002^{* *}$ \\
\hline [Small - Large] & $.021^{*}$ \\
\hline [Medium - Large] & .745 \\
\hline
\end{tabular}

Figure 4. Mean Sharing Resources Per-Staff-Member, Resolved by Operator Size and Corresponding Contrast Tests. 


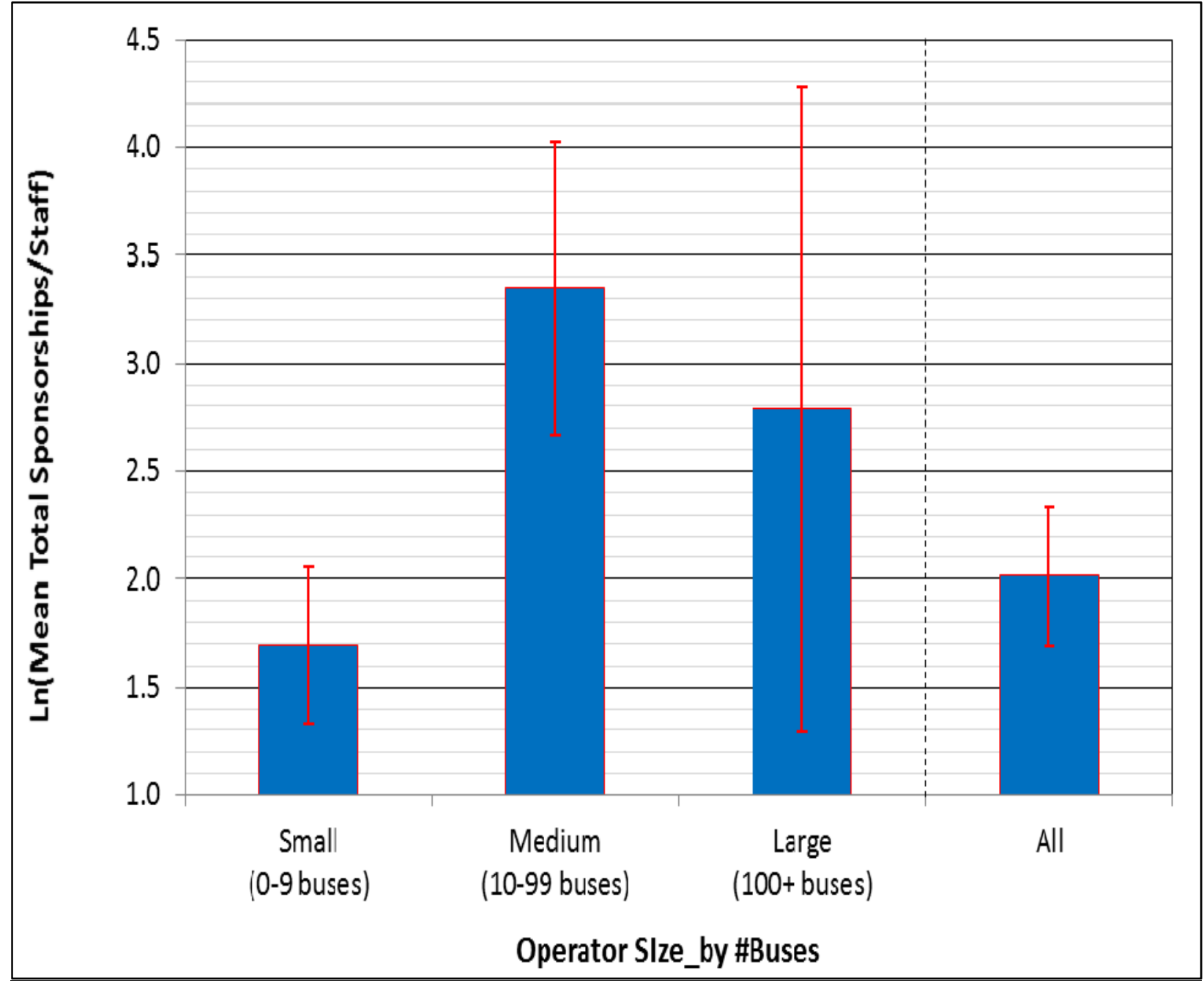

\begin{tabular}{|c|c|}
\hline \hline $\begin{array}{c}\text { Contrast } \\
\text { (Operator Size by \#Buses) }\end{array}$ & $\begin{array}{c}\text { Sig. value for } \\
\text { One-Way ANOVA Contrast Test } \\
\text { (Ln data values) }\end{array}$ \\
\hline$[$ Small-Medium] & $.000^{* *}$ \\
\hline$[$ Small-Large] & .187 \\
\hline [Medium-Large] & .506 \\
\hline
\end{tabular}

Figure 5. Mean Total Sponsorships Per-Staff-Member, Resolved by Operator Size and Corresponding Contrast Tests. 


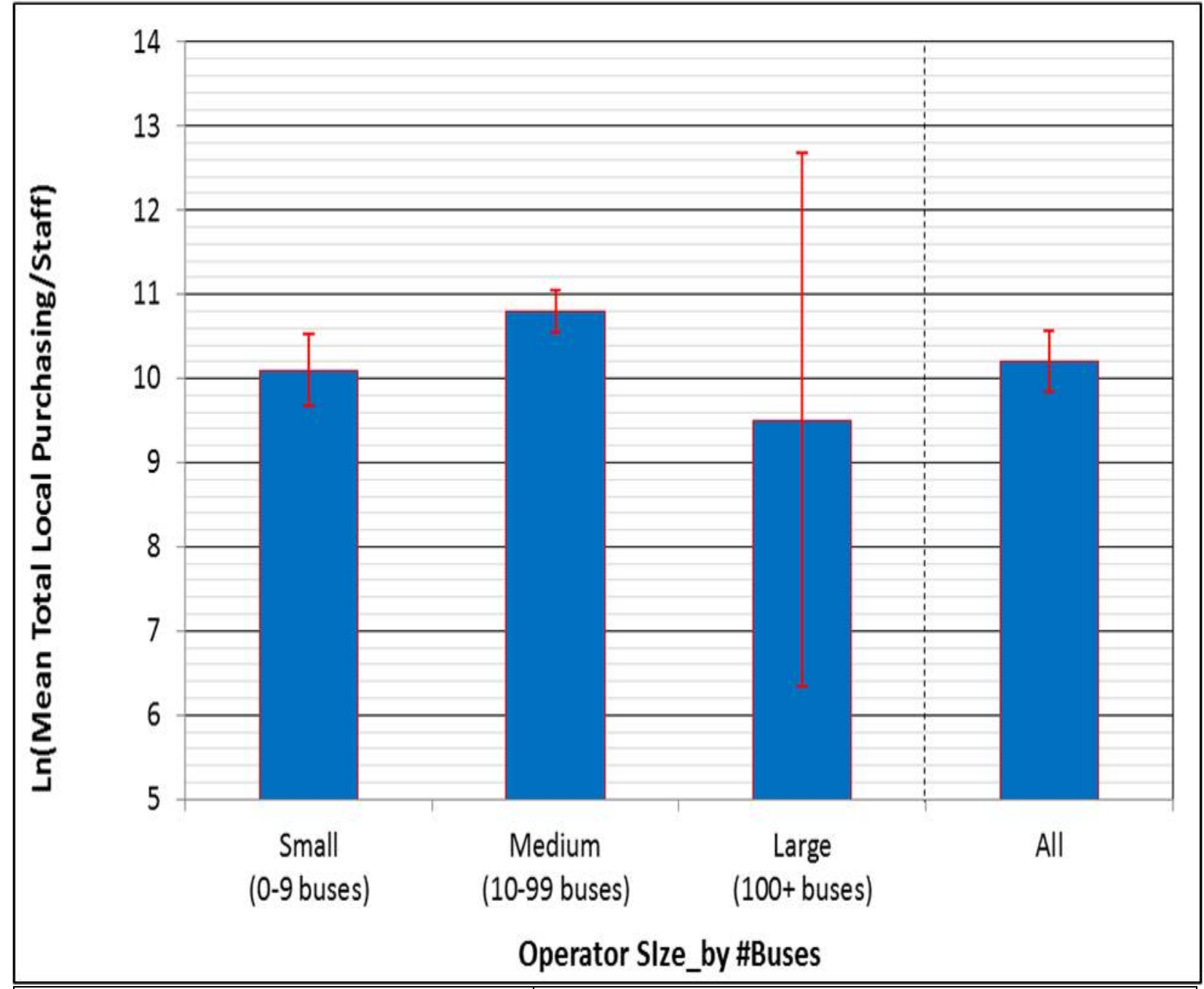

\begin{tabular}{|c|c|}
\hline \hline $\begin{array}{c}\text { Contrast } \\
\text { (Operator Size by \#Buses }\end{array}$ & $\begin{array}{c}\text { Sig. value } \\
\text { One-Way ANOVA Contrast Test } \\
\text { (Ln data values) }\end{array}$ \\
\hline$[$ Small-Medium] & $.005^{* *}$ \\
\hline$[$ Small-Large] & .723 \\
\hline$[$ Medium-Large] & .448 \\
\hline
\end{tabular}

Figure 6. Mean Local Purchasing Per-Staff-Member, Resolved by Operator Size and Corresponding Contrast Tests. 


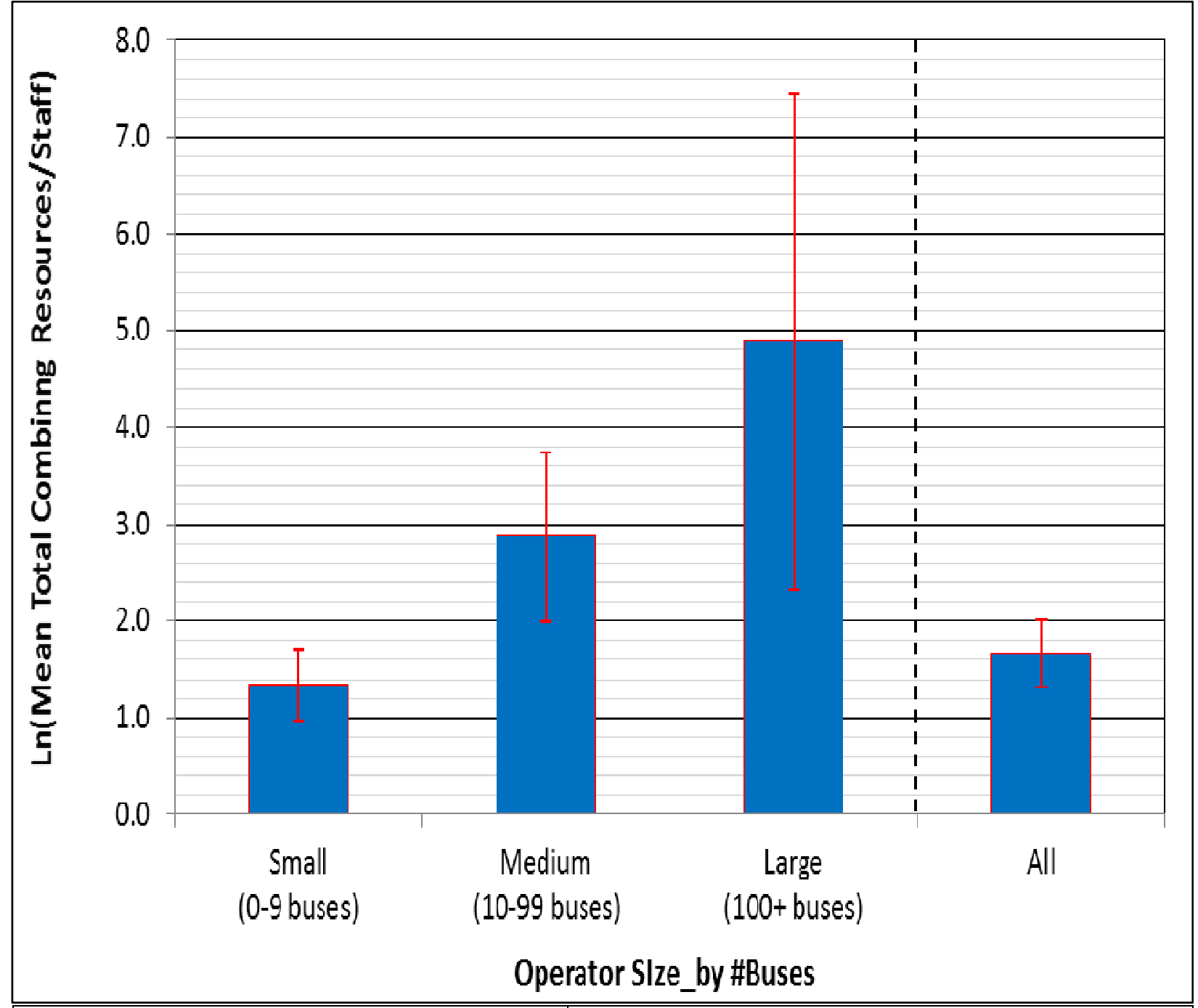

\begin{tabular}{|c|c|}
\hline \hline $\begin{array}{c}\text { Contrast } \\
\text { (Operator Size by \#Buses) }\end{array}$ & $\begin{array}{c}\text { Sig. value for One-Way ANOVA Contrast Test } \\
\text { (Ln data values) }\end{array}$ \\
\hline$[$ Small-Medium] & $.002^{* *}$ \\
\hline$[$ Small-Large] & $.039^{*}$ \\
\hline$[$ Medium-Large] & .187 \\
\hline
\end{tabular}

Figure 7. Mean Total Combining Resources Per-Staff-Member, Resolved by Operator Size and Corresponding Contrast Tests. 


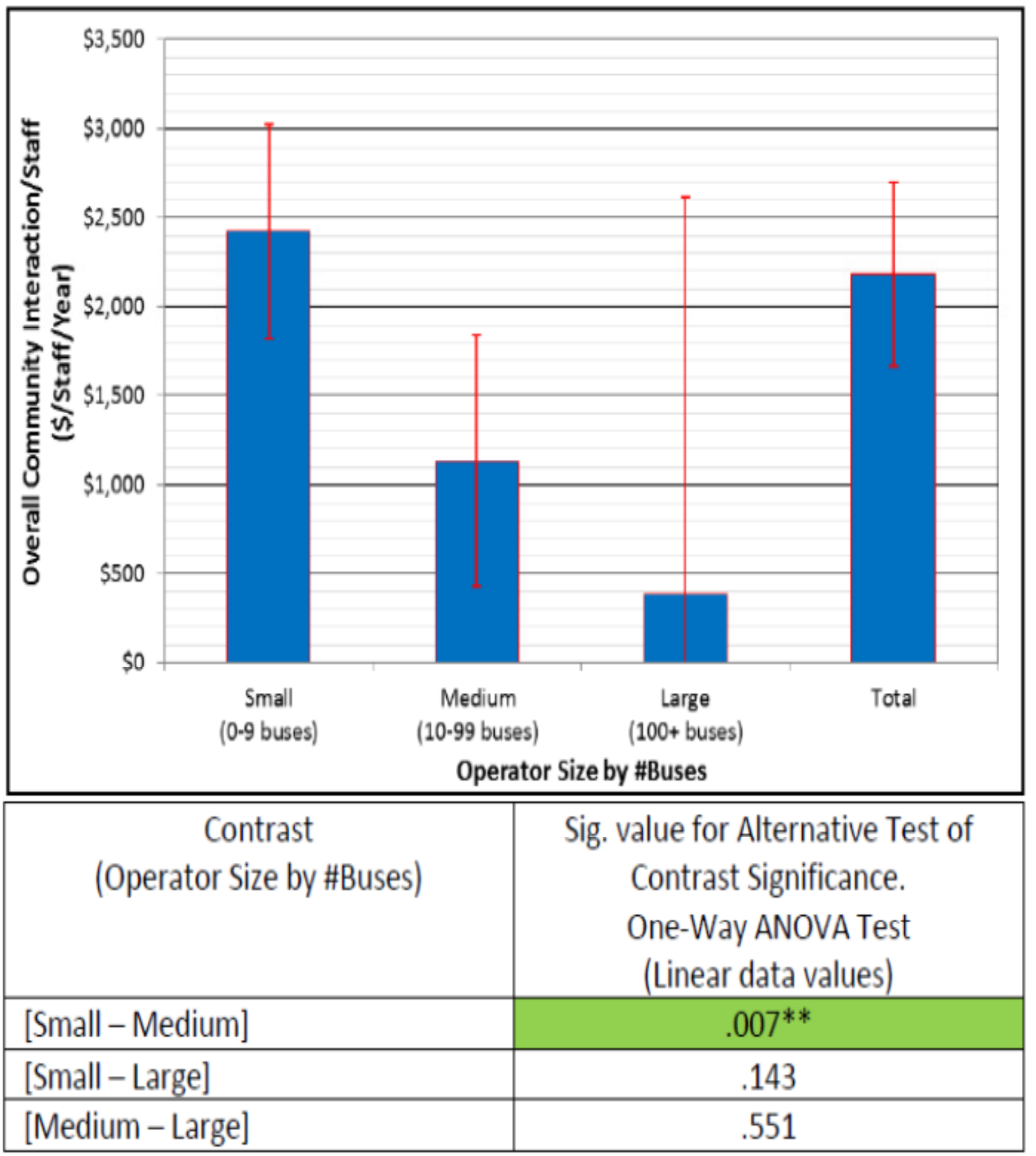

Figure 8. Combined Sum of Six Community Interaction Per-Staff-Member, Resolved by Operator Size and Corresponding Contrast Tests. 


\section{Small Operators}

The analysis reveals that the average individual financial and non-financial donation from a small operator to community stakeholders or individuals is $\$ 100.00$ greater than that of a medium operator and $\$ 200.00$ greater than that of a large operator. The staff of small operators also contribute more than six times the amount of time to community endeavours, such as the CFA, local boards, and philanthropic organisations, than do the staff of medium-sized operators and 22 times more than the staff of large operators. The variance between small operators and medium and large operators with respect to safety and security actions was significant, with small operator staff interactions showing an average of 14 times per year, compared with a medium-sized operators' 3.76 times per year and .57 times per year for a large operator. Small operators share their resources each year to an average value of $\$ 263.00$ for each staff member, while medium-sized operators share resources at a value of $\$ 90.80$ per staff member per year and large operators at $\$ 69.20$ per staff member per year. For three of the four interactions, the variance between small and medium operators is more than double. Notably, the analysis for all four of these community interactions is shown to be statistically significant.

Two of the four community interactions that reveal small operators as those who interact the most with their community on a per staff member basis are opportunity costs (income foregone due to the contribution of time and making resources available to local organisations and individuals), one is an actual cost incurred by the operator and the last (safety and security interactions) does not have a unit value and is measured by frequency, but it is an interaction nonetheless. This foregoing of income and the incurring of greater costs for four of the eight interactions confirms that small family firms are more prepared to reinvest locally and are willing to spend more money per staff member in these areas. This also suggests that the small operator does not place as much importance on financial outcomes as other family firms and perhaps does not value firm growth as much as medium or large operators do; rather, they value continuity over profit.

\section{Medium Operators}

Two of the three community interactions in which the staff of medium-sized family firms interact the most were related to the actual costs incurred: sponsorships and local purchasing. The other, discounted services, was an opportunity cost. In terms of discounted services and sponsorships, medium-sized family firms were shown to interact the most with their community, just ahead of small family firms. This suggests that medium-sized operators' community interaction and orientation are more akin to that of a small operator than a large operator. It could be argued that these are operators who started small, but have purposefully grown their business and have started to pursue and realise scale economies, but still very much value the community interaction.

\section{Large Operators}

The analysis confirms that large firms combine their resources with other operators more often than small and medium operators, most likely because they have the resources to satisfy the demand for large-scale projects such as rail-replacement services. Notably, the variance between large firms and medium and small family firms was not marginal: large firms attract nearly $500 \%$ more revenue than small- and medium-sized family firms when combining resources. Further, the analysis reveals that large family firm operators came in second in one community interaction, local purchasing, and only by a margin of less than $5 \%$ of medium operators. Given that the combination of resources was the only community interaction that was measured in terms of revenue 
generation, and that a large operator's second strongest community interaction was cost-related, such a focus on financial management suggests that large operators place a higher value on financial performance than small- and medium-sized firms.

It is also noted that seven out of the eight contrast tests were statistically significant, suggesting a high degree of reliability. As a result, it can be concluded that there is a low probability that seven of the eight observed effects occurred due to chance. It is therefore found that this study's hypothesis - a bus operator's community interaction diminishes as firm size increases, is supported.

\section{DISCUSSION}

This study tested whether firm size affects the extent of a firm's interaction with its community in the context of the Australian bus- and coach-operating environment. The results confirm that firm size does matter when it comes to linking governance with community and regional development. With respect to the eight individual community interactions measured in this survey, small operators interact the most with their community on a per staff member basis in four ways, medium-sized operators interact the most with their community on a per staff member basis in three ways and large operators interact the most with their community in one type of community interaction only. On an aggregated basis (excluding safety interactions and local purchasing), small firms interact with their community the most, followed closely by medium-sized firms, then followed by large firms. This study also confirms that large firms' community interactions are financial-centric, whereas the goals of the small and medium family firms are more socioeconomic-centred.

The results of this study show that the behaviour of small- and medium-sized family firms are the governance models most likely to contribute toward achieving community and regional development outcomes due to their higher concern for community welfare. Other scholars have made similar assertions: Lyson (2006) and Irwin, Lyson, and Tolbert (1998), for example, demonstrate that communities in which small businesses predominate have a higher level of civic welfare than communities that are dominated by big business. Fleming and Goetz (2011) also reveal a positive relationship between the density of locally owned firms and per capita income growth, but only for small firms, as the density of large non-locally owned firms has a negative effect.

In Australia, communities are made up of individuals and local institutions and organisations, including businesses, schools, voluntary associations, and churches. These networks of smaller enterprises are linked together by community conditions and are as much embedded in the locality as the local families. As a result of this "embeddedness", small firms are less likely to remove themselves from the local community during economic downturns and are more likely to provide support, membership, and direction for local institutions. In light of the results of this study, it is suggested that it is possible that the melding of a social economy would create greater benefit for the community and this would offset any gains in economic efficiency achieved by large, particularly non-family firms.

The results of this study also underscore the importance placed on the achievement of the non-financial goals of family firms and the socio-emotional wealth of the community in which the firm is embedded. Contributing to one's community in order to sustain or improve its wellbeing is a key theme running through the qualitative responses to this study's survey. The importance of the non-economic goals of family firms is also reinforced in Chrisman, Chua, and Steier (2011), Colli (2012), and $\mathrm{Yu}$ et al. (2012). Socio-emotional wealth may take several forms: an ability to provide careers and security for current and later generations, community, visibility, status, and even harmony within the family. 
It is suggested that this desire for continuity in family firms embodies a family firm's desire for long-term family control, secure family careers, and a participatory community.

\section{CONCLUSIONS}

This study individually quantifies the value of eight community interactions of family firm bus and coach operators in Australia and presents an aggregated total of six, as two of the interactions have been excluded from the total summation. The study shows how small and medium family firm bus operators are more likely to interact with their communities on a per employee basis and that these, therefore, represent governance models that are more likely to contribute toward achieving outcomes in line with community and regional development initiatives. This firm behaviour highlights the importance placed on the achievement of the non-financial goals of family firms and the value they place on the socio-emotional wealth of the community in which the family firm is embedded.

In light of these results, it seems plausible for Australian Governments to adopt new policies, or to enhance existing ones, that will sustain the small to medium family firm as a bus operator governance model in order to ensure a greater likelihood of achieving community and regional development objectives in Australia. In order to achieve this, it is unlikely that top-down ideas and theories will work; for example, a government that decides to competitively tender bus services and award contracts to firms based solely on price will most likely give business to large, non-family firms. This study (and others) show(s) that these firms are less likely to interact with a community on a per employee basis than a small- or medium-sized family firm. Such a measure would, therefore, work against community and regional development endeavours. It is thus recommended that the government engage with itself and community and industry stakeholders to find a more effective way for bus service procurement regimes to realise whole-of-government objectives, including community and regional development, rather than simply procuring transport services for the lowest possible price.

\section{Notes}

1. No state-specific analysis forms part of this study, however, it will form part of the author's doctoral research project.

2. This very frequently applied approach is known to markedly reduce the effect of outliers and departures from normality in the identification of statistically significant differences between means. That is, it is known to be more robust than the standard approach, without applying the log transform.

\section{References}

Aldrich, D. 2011. "The Externalities of Strong Social Capital: Post-tsunami Recovery in Southeast India." Journal of Civil Society 7(1):81-99. Retrieved (http://works.bepress.com/ daniel_aldrich/11).

Australian Bureau of Statistics (ABS). 2013. Glossary 8155.0-Australian Industry. Retrieved March 10, 2014 (http://www.abs.gov.au/ausstats/abs@.nsf/Lookup/8155.0G lossary 12011-12).

Birley, S. and D. Norburn. 1993. "Small vs. Large Companies: The Entrepreneurial Conundrum." Journal of Business Strategy 6(1):81-87.

Cavaye, J. 2014. "Understanding Community Development." Cavaye Community Development. Retrieved (http://www. communitydevelopment.com.au/Documents/Understanding \%20Community\%20Development.pdf).

Chrisman, J., J. Chua, and L. Steier. 2011. "Resilience of Family Firms: An Introduction." Entrepeneurship: Theory and Practice 35(6):1107-1119.

Colli, A. 2012. "Contextualizing Performances of Family Firms: The Perspective of Business History." Family Business Review 25(3):243-247.

Dumaine, B. and J. Labate. 1992. "Is Big Still Good?” Fortune Magazine. Retrieved (http://money.cnn.com/magazines/ fortune/fortune_archive/1992/04/20/76316/).

Eapen, A. 2012. "Social Structure and Technology Spillovers From Foreign to Domestic Firms." Journal of International Business Studies 43:244-263.

Family Business Australia. 2013. Family Businesses in Australia-Different and Significant: Why They Shouldn't Be Overlooked. Parliamentary Joint Committee on Corporations and Financial Services, Senate Printing Unit, 
Parliament House, Canberra.

Fleming, D. A. and S. Goetz. 2011. "Does Local Firm Ownership Matter?" Economic Development Quarterly 25(3):277-281.

Gama, A. P. M. and J. M. M. Galvao. 2012. "Performance, Valuation and Capital Structure: Survey of Family Firms." Corporate Governance 12(2):199-214.

Grinols, E. L. and D. B. Mustard. 2001. "Business Profitability Versus Social Profitability: Evaluating Industries With Externalities-The Case of Casinos." Managerial and Decision Economics 22(1):143-162.

Irwin, M., T. Lyson, and C. Tolbert. 1998. "Local Capitalism, Civic Engagement and Socioeconomic Well-being." Social Forces 77(2):401-428.

Kotkin, J. 2000. "The Rise and Fall of the Big, Bureaucratic Corporation." The American Enterprise 11(1):30.

Lawler, E. and J. Galbraith. 1995. "Avoiding the Corporate Dinosaur Syndrome." Organisational Dynamics 23(2):5-17.

Lyson, T. 2006. "Big Business and Community Welfare: Revisiting a Classic Study by C. Wright Mills and Melville Ulmer." American Journal of Economics and Sociology 65(5):1001-1024

McCall, T. 2010. "What Do We Mean by Regional Development?" Institute of Regional Development, University of Tasmania.

Moates, W. and D. Kulonda. 1990. "An Examination of Differences Between Supervisors in Large and Small Companies." Journal of Small Business Management 28(3):27.

National Institute of Economic and Industry Research (NIEIR). 2009. The Economic Contribution of the Bus Industry to Victoria by Local Government Area: Part One-The Operational Contribution. Retrieved (http://www.busvic. asn.au/images/uploads/public/NIEIR_2010_Economic_cont ribution_of_bus_in_Vic_part_1_final_report.pdf).

- 2011. Melbourne Route Bus Contracts: The Impact of Change From Local to Non-local Ownership. Retrieved (http://www.busvic.asn.au/images/uploads/public/45603_bu svic_contracts_booklet.pdf).

OECD (Organization for Economic Co-operation and Development). 2014. Regional Development. Retrieved (http://www.oecd.org/gov/regional-policy/regionaldevelop ment.htm).
Salvato, C. and H. E. Aldrich. 2012. "That's Interesting!" Family Business Review 25(20):125-135.

Shanker, M. C. and J. H. Astrachan. 1996. "Myths and Realities: Family Businesses; Contribution to the U.S. Economy-A Framework for Assessing Family Business Statistics." Family Business Review 9(20):107-109.

Sharma, P., J. Chrisman, and G. Gersick. 2012. "25 Years of Family Business Review: Reflections on the Past and Perspectives for the Future." Family Business Review 25(1):5-15.

Sinani, E. and K. Meyer. 2004. "Spillovers of Technology Transfer From FDI: The Case of Estonia." Journal of Comparative Economics 32(3):445-466.

Sorenson, R. 2013. "How Moral and Social Values Become Embedded in Family Firms." Journal of Management, Spirituality and Religion 10(2):116-137.

Sorenson, R. L., K. E. Goodpaster, P. R. Hedberg, and A. Yu. 2009. "The Family Point of View, Family Social Capital, and Firm Performance: An Exploratory Test." Family Business Review 22(3):239-253.

Speckbacher, G. and P. Wentges. 2012. "The Impact of Family Control on the Use of Performance Measures in Strategic Target Setting and Incentive Compensation: A Research Note." Management Accounting Research 23(1):34-46.

Vossen, R. W. 1998. "Relative Strengths and Weaknesses of Small Firms in Innovation." International Small Business Journal 16(3):88-94.

Williams, Z. 2013. The Shadow State: A Report About Outsourcing of Public Services. Social Enterprise UK.

Winger, A. R. 1994. "Is Big Really Bad?" Business Economics 29(3):38-42.

Yu, A., G. T. Lumpkin, R. L. Sorenson, and K. H. Brigham. 2012. "The Landscape of Family Business Outcomes: A Summary and Numerical Taxonomy of Dependent Variables." Family Business Review 25(1):35-57.

\section{Bio}

Christopher Lowe, M.B.A. (C.S.U., 2006), Ph.D. candidate at Monash Sustainability Institute, Melbourne, Australia, executive director, Bus Association Victoria Inc. (Australia); research fields: social externalities, governance, family businesses, bus industry, and voluntary professional associations. 